\title{
Effect of strain rate on the compression behavior of a woven glass fiber/SC-15 composite
}

\author{
M. Guden ${ }^{\mathrm{a}, \mathrm{b}, *}$, U. Yildirim ${ }^{\mathrm{a}}$, I.W. Hall ${ }^{\mathrm{c}}$ \\ a Mechanical Engineering Department, Izmir Institute of Technology, Izmir, Turkey \\ ${ }^{\mathrm{b}}$ Center for Materials Research, Izmir Institute of Technology, Izmir, Turkey \\ c Mechanical Engineering Department, University of Delaware, Newark, DE, USA
}

Received 14 October 2003; accepted 3 January 2004

\begin{abstract}
Strain rate dependent compression behavior of a plain-weave S-2 glass fabric SC-15 epoxy (rubber toughened resin) composite plate, currently studied as the backing plate for composite armor applications, was determined in the through-thickness direction (normal to the fiber plane) in the strain rate regime of $1 \times 10^{-4}$ to $1.1 \times 10^{3} \mathrm{~s}^{-1}$. In the studied strain rate regime, the modulus and failure strength of the composite were found to be rate sensitive and increased with increasing strain rate. Microscopic observations showed that the composite failed by ductile failure, involving matrix cracks and, later, cracking through and between the fiber layers. Crack deflections at rubber particle/matrix interface and particle pull-out were observed in the failed samples, contributing to the toughness of the composite.
\end{abstract}

(C) 2004 Elsevier Ltd. All rights reserved.

Keywords: S-2 glass; SC-15 epoxy; Composite; Compression; High strain rate

\section{Introduction}

Modern composite armor, typically consisting of a combination of a hard facing layer of ceramic tiles and a fiber reinforced composite backing plate, is under development to satisfy ballistic and structural requirements, while providing weight savings of approximately $30-40 \%$ [1]. The function of the ceramic layer is to deform and erode the projectile and thereby reduce the local pressure in the composite backing plate. The composite layer absorbs a significant part of the kinetic energy of the projectile by a variety of deformation processes. A thin rubber layer between the ceramic and composite improves multi-hit capability and a single layer of glass reinforced composite spall shield is bonded to the impact face of the ceramic to suppress

\footnotetext{
* Corresponding author. Tel.: +90-232-498-6595; fax: +90232-498-6505.

E-mail address: mustafaguden@iyte.edu.tr (M. Guden).
}

forward spall generation and preserve the mechanical integrity of the armor [1].

During projectile impact, stress wave propagation occurs through and between the different layers of armor. The magnitude and the shape of propagating stress waves depend on the acoustic impedance of individual layers. In the initial few microseconds, a compressive wave is generated and propagates through the ceramic-facing layer in the impact direction. This compressive wave partly reflects back from the ceramiccomposite interface to the ceramic layer as a tensile wave and the remaining part propagates through the composite backing plate and deforms it at relatively high strain rates. Subsequent reflections from interfaces and free surfaces further complicate the wave propagation events. Finite Element Analysis (FEA) modeling of these complex wave propagation events necessitates the utilization of high strain rate mechanical property data of the layer materials for more realistic calculations. This study was, therefore, conducted to obtain high strain rate compressive mechanical property data 
and deformation behavior of a woven fabric glass fiber polymeric composite which is currently studied as a backing plate in composite armor.

\section{Material and testing method}

S-2 glass fiber woven fabric $\left(24 \mathrm{oz} \cdot / \mathrm{yd}^{2}\right) / \mathrm{SC}-15$ epoxy (toughened resin) composite plate of $12.23 \mathrm{~mm}$ thickness was produced using the vacuum assisted resin transfer molding process at the Center for Composite Materials, University of Delaware. Metallographic samples from the as-fabricated composite plate were initially prepared and observed under an optical microscope. Fig. 1 shows a cross-section micrograph of the composite plate.

Cylindrical composite samples $11.27 \mathrm{~mm}$ in diameter were core-drilled from the plate in the through-thickness direction and were compression tested at varying strain rates between $1.4 \times 10^{-4}$ and $1.1 \times 10^{3} \mathrm{~s}^{-1}$ (the compression axis normal to fiber plane). Quasi-static tests $\left(1.4 \times 10^{-4}\right.$ to $\left.8 \times 10^{-2} \mathrm{~s}^{-1}\right)$ were performed on a Shimadzu AG-I testing machine. High strain rate tests $\left(>100 \mathrm{~s}^{-1}\right)$ were conducted using a split-Hopkinson pressure bar (SHPB) apparatus. The SHPB apparatus used consists of Inconel 718 bars, $326 \mathrm{~mm}$ striker, $3450 \mathrm{~mm}$ incident and $1850 \mathrm{~mm}$ transmitter bars, all with a diameter of $19 \mathrm{~mm}$. Detailed information about the SHPB used is given in [2]. The strain rate $(\dot{\varepsilon})$, the strain $(\varepsilon)$ and the stress $(\sigma)$ of the tested sample were calculated using the following equations:

$$
\begin{aligned}
& \dot{\varepsilon}(t)=-\frac{2 C_{\mathrm{b}}}{L_{\mathrm{s}}} \varepsilon_{\mathrm{r}}(t) \\
& \varepsilon(t)=-\frac{2 C_{\mathrm{b}}}{L_{\mathrm{s}}} \int_{0}^{t} \varepsilon_{\mathrm{r}}(t) \\
& \sigma(t)=\frac{E_{\mathrm{b}} A_{\mathrm{b}}}{A_{\mathrm{s}}} \varepsilon_{\mathrm{t}}(t)
\end{aligned}
$$

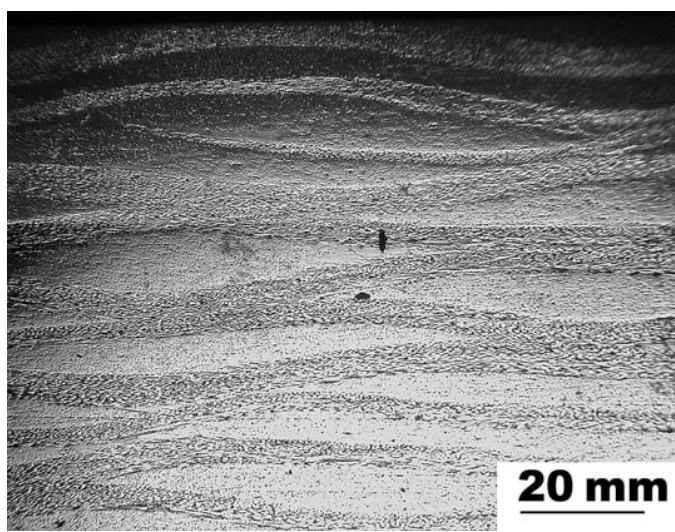

Fig. 1. Optical micrograph of the cross-section of the composite plate. where $C_{\mathrm{b}}$ is the elastic wave velocity in the bar, $L_{\mathrm{s}}$ is the sample length and $A_{\mathrm{s}}$ and $A_{\mathrm{b}}$ are the sample and bar cross-sectional areas, respectively. $\varepsilon_{\mathrm{i}}, \varepsilon_{\mathrm{r}}$ and $\varepsilon_{\mathrm{t}}$ are incident, reflected and transmitted strains measured from strain gages on the bar, respectively. The above equations are based on the assumption that the forces at sample-bar interfaces are equal. The force equilibrium for the same incident and transmitter bars diameter is expressed as

$\sigma_{\mathrm{t}}(t)=\sigma_{\mathrm{i}}(t)+\sigma_{\mathrm{r}}(t)$

where $\sigma_{\mathrm{t}}, \sigma_{\mathrm{i}}$ and $\sigma_{\mathrm{r}}$ are the transmitted, incident and reflected stresses, respectively. The left and right side of this equality are used in the so-called "one-wave" and "two-wave" analyses, respectively. Stress equilibrium within the sample is considered to be reached after 3-4 back and forth reflections of the wave in the sample and the time at which equilibrium is established depends on the wave transit time of the sample [3]. Since the transmitter bar of the SHPB we used is shorter than the incident bar, the tensile wave reflected from the transmitter bar end separates the bars and, therefore, the sample deforms only once under compression.

Composite samples, compressed to failure, were cut and prepared for microscopic analysis. Typical damage mechanisms operative prior to and during failure were determined using microscopy techniques.

\section{Results and discussion}

Typical SHPB strain readings of a tested composite sample are shown in Fig. 2, together with strain reading of a strain gage mounted on the sample. Time-shifted strain data from strain gages mounted on the sample are found to be in excellent agreement with calculated SHPB strains (Fig. 3), proving the reliability of sample strain measurements taken from the SHPB used. The following figures, Fig. 4(a) and (b) are examples of tests that do and do not satisfy Eq. (4), respectively. The sample tested at about $1.4 \times 10^{3} \mathrm{~s}^{-1}$ in Fig. 4(b) failed before stress equilibrium was attained and was, therefore, disregarded. It was experimentally found that above an average strain rate of $1.2 \times 10^{3} \mathrm{~s}^{-1}$, the samples did not attain stress equilibrium until failure and, therefore, tests above this strain rate may not show the true material property.

Typical engineering stress/strain and strain rate/ strain curves of the composite tested in the SHPB are shown in Fig. 5(a). For a specific test, the instantaneous strain rate varied during deformation, from zero to final or failure strain, and therefore an average strain rate was calculated as

$\dot{\varepsilon}_{\text {avg }}=\frac{1}{\varepsilon_{\mathrm{f}}} \int_{0}^{\varepsilon_{\mathrm{f}}} \dot{\varepsilon} \mathrm{d} \varepsilon$ 


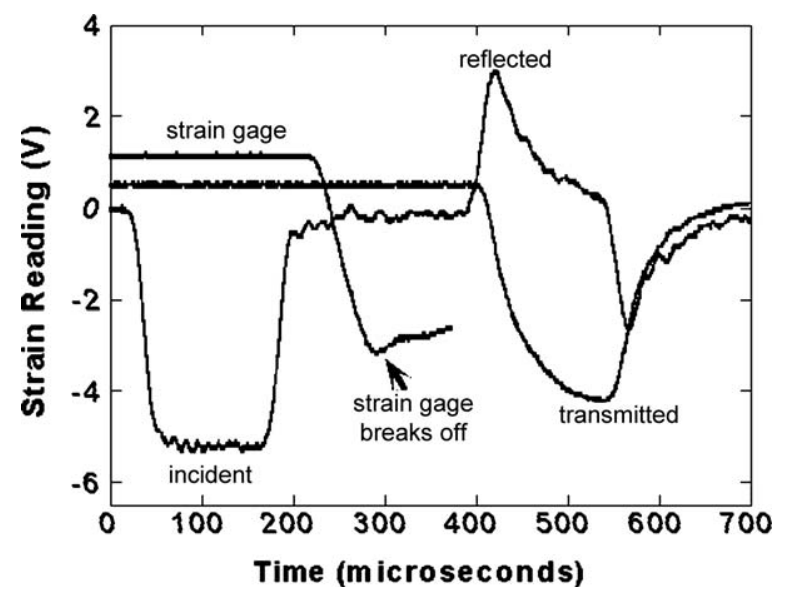

Fig. 2. SHPB strain gages and sample strain gage readings as function of time.

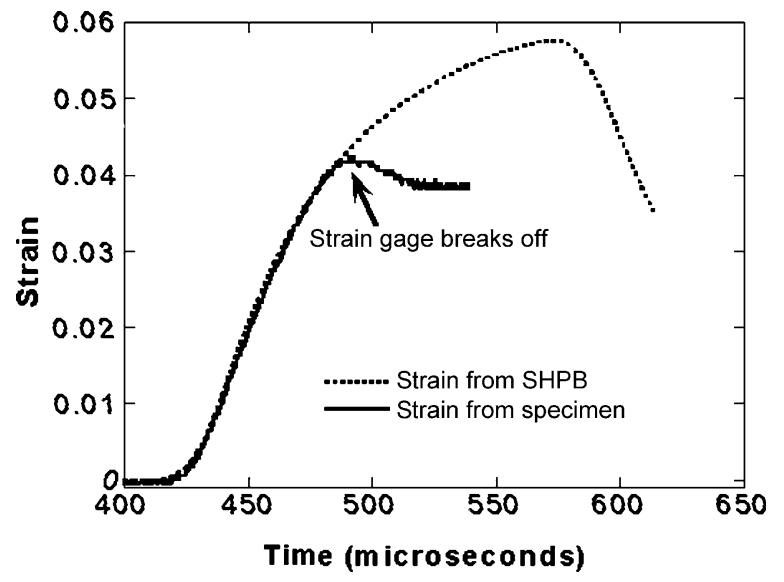

Fig. 3. Comparison of sample strain measurement of SHPB and strain measurement from the sample strain gage.
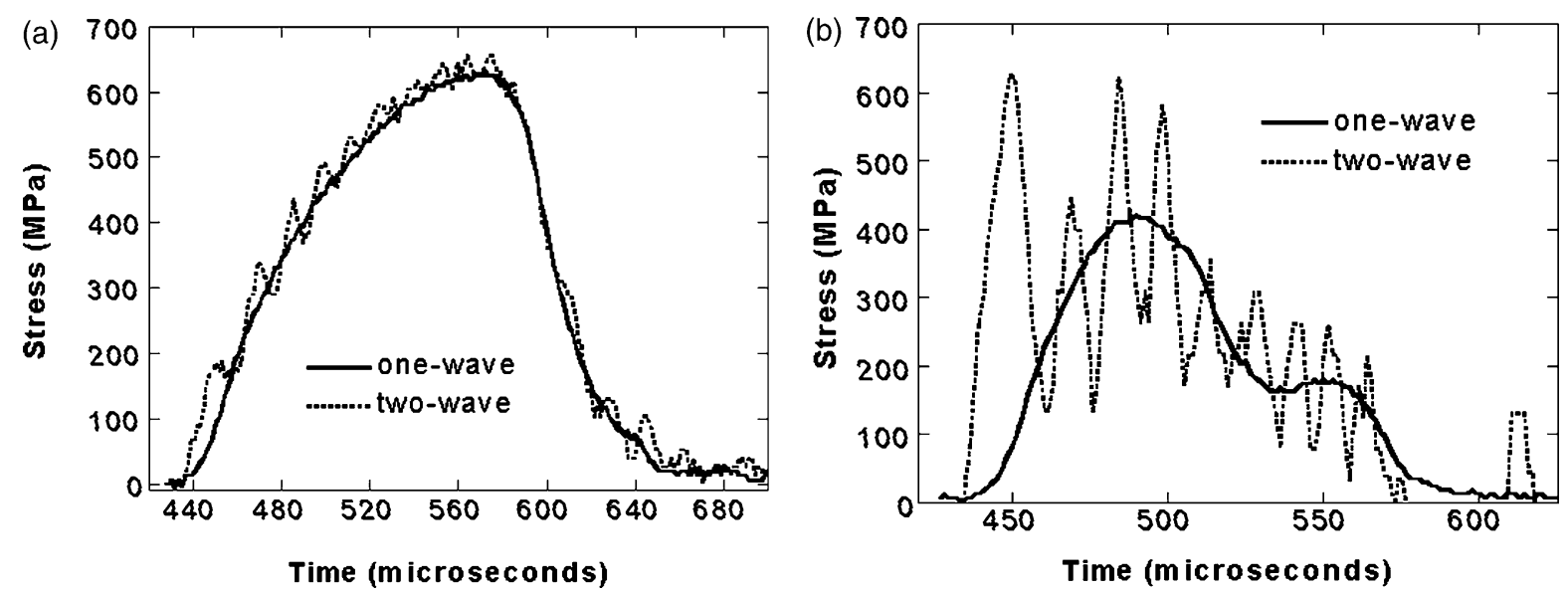

Fig. 4. One-wave and two-wave stress values for (a) a sample satisfying Eq. (4) and (b) a sample not satisfying Eq. (4). 

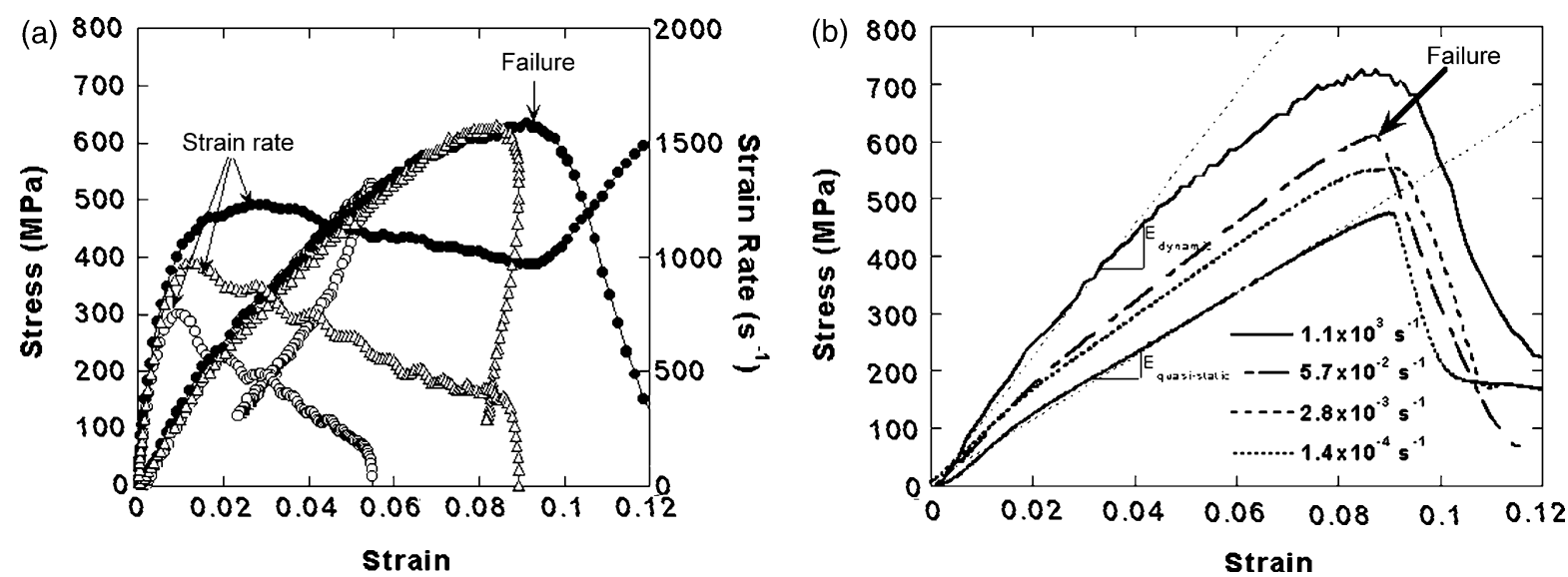

Fig. 5. (a) Stress/strain and strain rate/strain behavior of the composite tested in SHPB and (b) stress/strain curves of the composite at different strain rates.

where $\varepsilon_{\mathrm{f}}$ is the maximum strain. Tested composite specimens did not fail until strains of $8-9 \%$ and showed a viscoelastic stress/strain behavior (Fig. 5(a)). Fig. 5(b) shows the typical compressive stress/strain curves of the composite tested between the quasi-static and the high strain rates. The modulus of the composite samples was calculated in the linear region of the curves at a strain of $4 \%$, i.e., approximately halfway to failure (see Fig. 5(b)), and used to determine the effect of strain rate on the modulus of the composite throughthickness direction. The maximum points on these figures, as marked with arrows, are considered as the failure stresses and the corresponding strains as the failure strains.

The approximate modulus of the composite calculated from Fig. 5(b) was found to be strain rate sensitive (Fig. 6(a)). The average modulus of the composite increases from 6 to $10 \mathrm{GPa}$ as the strain rate increases from quasi-static $\left(1.4 \times 10^{-4} \mathrm{~s}^{-1}\right)$ to high strain rates $\left(1.1 \times 10^{3} \mathrm{~s}^{-1}\right)$. Within the studied strain rate regimes, the average failure stress of the composite also increases with increasing strain rate from quasi-static to high strain rates (Fig. 6(a)); 450 to $700 \mathrm{MPa}$. The average failure strain, however, decreases slightly with increasing strain rate from quasi-static to high strain rates: 0.088 at $1.4 \times 10^{-4} \mathrm{~s}^{-1}$ to 0.084 at $1.1 \times 10^{3} \mathrm{~s}^{-1}$ (Fig. 6(b)). The composite material tested at high strain rates has a failure strength of 600-700 $\mathrm{MPa}$ and failure strain of $\sim 8 \%$, which are comparable with the failure strength and strain of a similar vinyl ester/glass fiber composite ( 700 $\mathrm{MPa}$ and 5-10\%) tested in the same direction by Gama et al. [4] and Akil et al. [5].

Fig. 7 shows a typical fractured composite sample, recovered from the SHPB, illustrating the common macroscopic appearance of such samples. Extensive cracking has occurred at interlaminar boundaries,
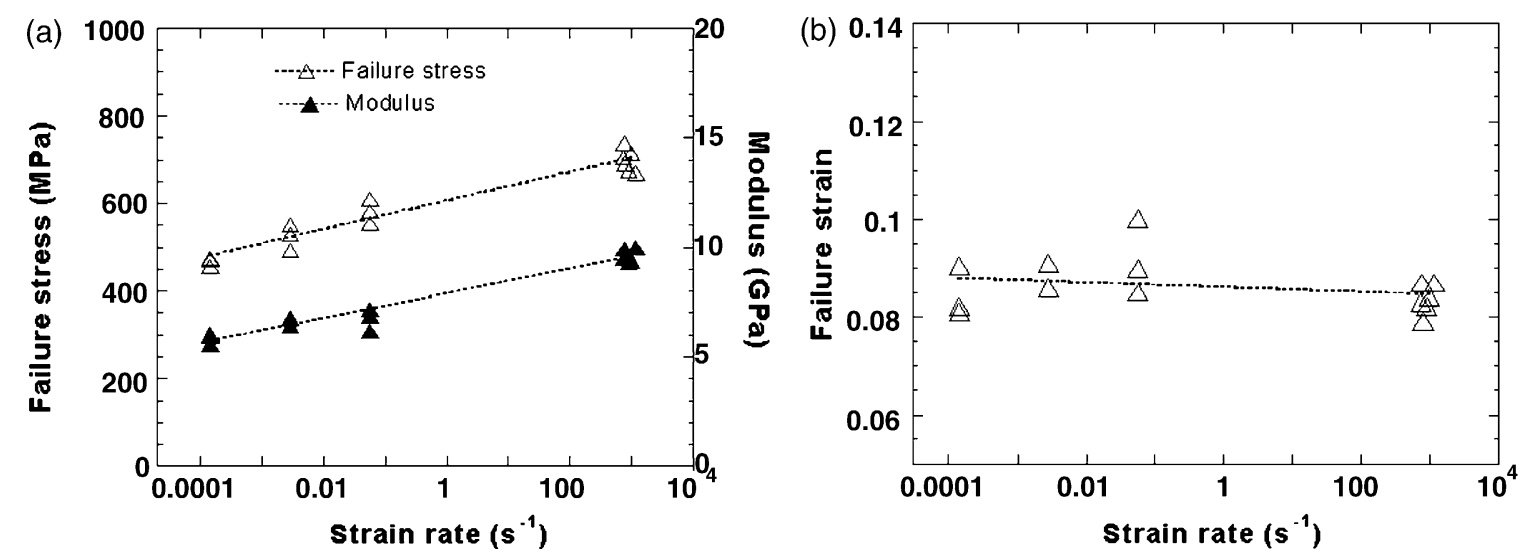

Fig. 6. (a) Failure stress and modulus and (b) failure strain vs. strain rate. 


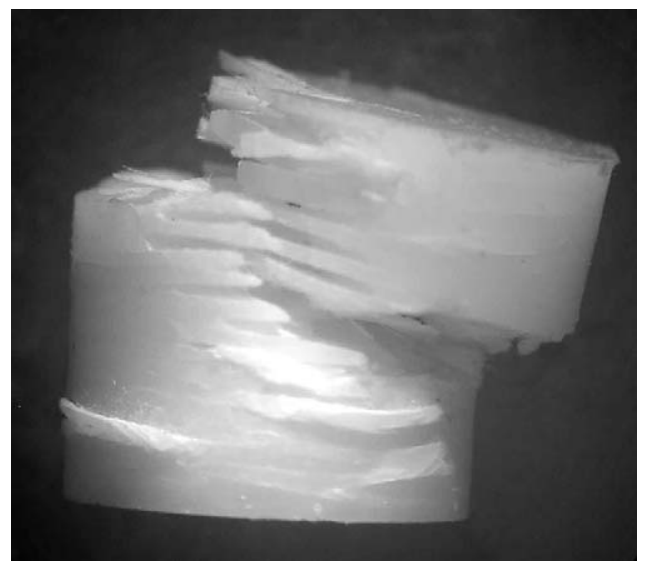

Fig. 7. A failed composite sample tested at $1.1 \times 10^{3} \mathrm{~s}^{-1}$.

resulting in adjoining layers being displaced and squeezed out in different directions and giving rise to a "dovetail" appearance. Fig. 8(a) shows polished crosssections of the fractured sample. The dark lines in the dark-field micrograph correspond to cracks between the fiber layers and also show progressive shear cracks in the matrix (Fig. 8(b)). The final failure was at $\sim 45^{\circ}$ to the loading axis and the flat regions near to the surface on the fracture path are regions where fiber layers have been squeezed out from the surface and lost (Fig. 8(a)). It is also noted that the matrix failure is relatively ductile, featuring small fractured pieces of the matrix (Fig. 9(a)). The presence of the rubber particles

(a)

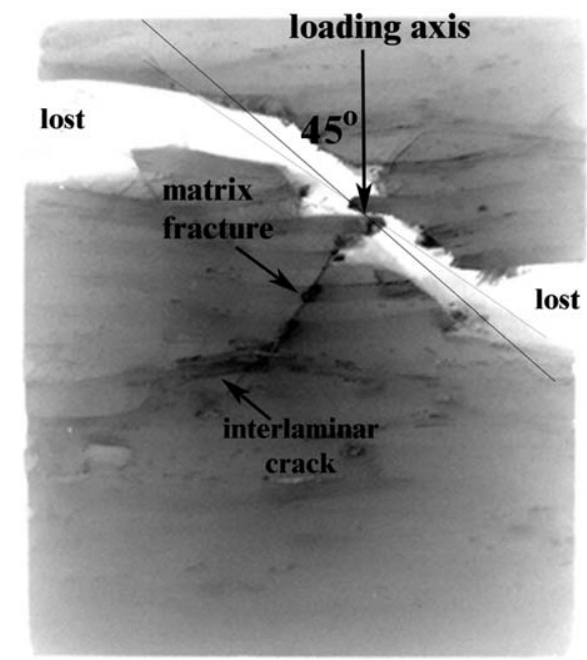

on the fracture surface and microcracks around rubber particles (Fig. 9(b)) confirmed the effect of these particles on the toughness of the composite. Mechanisms that are identified to contribute to the composite toughness include the crack deflection (Fig. 9(b); marked by arrow) and particle pull-out (Fig. 9(c)). Above observations are valid both for quasi-statically and dynamically tested composite samples, since the deformation mode is observed to remain the same in the studied strain rate regime.

The strain rate effect on the deformation behavior of fiber reinforced polymer composites was reviewed by Sierakowski [6]. Strain rate has generally been found to increase both modulus and failure stress. Hosur et al. [7] have recently studied the effect of strain rate on the woven carbon fiber reinforced SC-15 matrix composite through the in-plane direction and showed that both modulus and failure stress increased significantly with increasing strain rate from quasi-static to $\sim 1 \times 10^{3} \mathrm{~s}^{-1}$. It should also be noted that the failure mechanisms of composites tested in-plane can be quite different from those normal to the fiber plane. In the former, failure mostly occurs via fiber buckling and axial splitting $[4,8,9]$ whereas the latter fails principally via shear fracture of the matrix $[4,10]$. The effect of strain rate on the failure mode in the in-plane direction was found to change the failure mode from fiber buckling at quasistatic strain rates to fiber buckling and axial splitting at dynamic strain rates in glass fiber reinforced vinyl ester composite [5,11]. In the direction normal to the fiber plane, it was found that the deformation mode remained the same for quasi-static and dynamic strain (b)

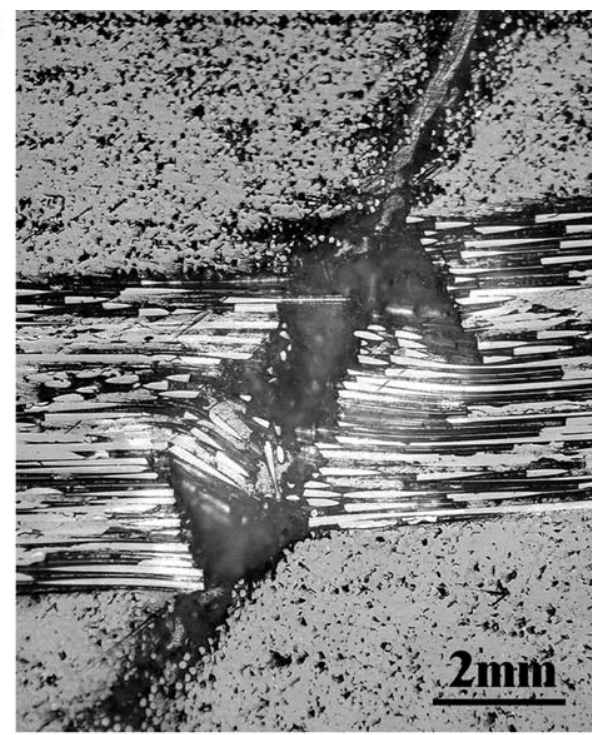

Fig. 8. (a) Dark-field (negative) polished cross-section of a failed composite sample and (b) matrix shear cracking in the region shown by arrow in (a). 
(a)

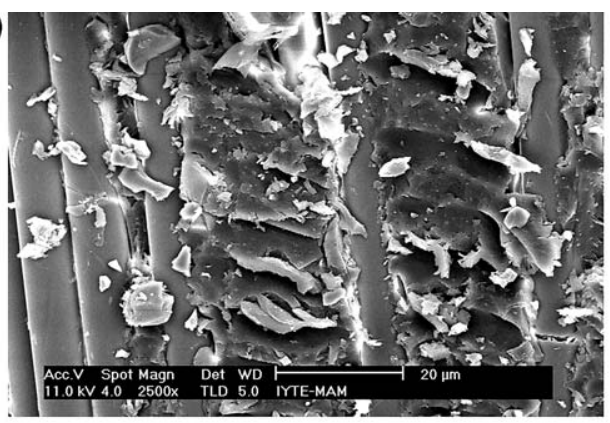

(b)

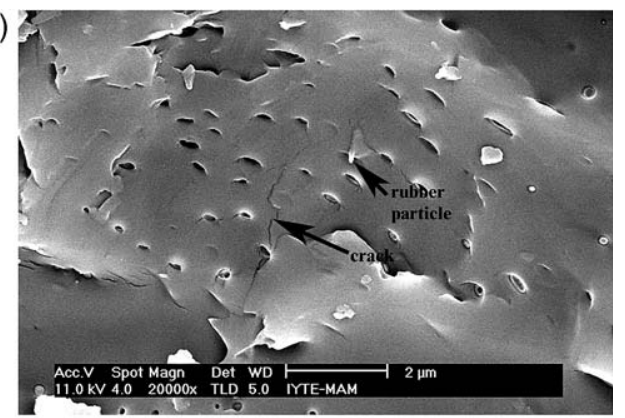

(c)

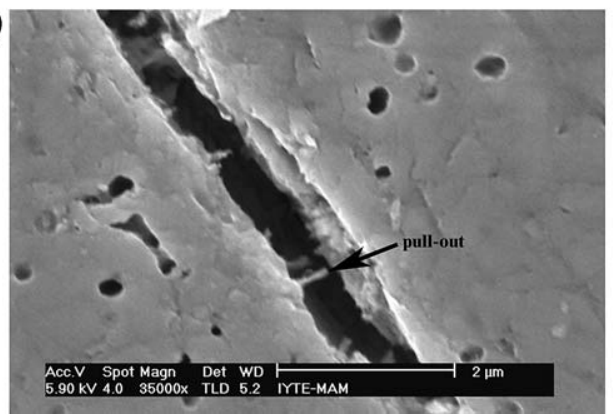

Fig. 9. Scanning electron micrograph of the failed composite sample showing (a) matrix fracture and (b) and (c) effects of rubber particles.

rates. Since, the properties of the composite in this direction are dominated by the matrix, the matrix ratesensitive properties will also be expected to affect the dynamic properties of the composite.

The composite showed ductile failure, involving matrix cracks and, later, cracking through and between the fiber layers. The presence of debonded and pulledout rubber particles on the fracture surface confirmed the effectiveness of the rubber particles in increasing toughness of the composite. These deformation features in fact indicate the composite's capability to absorb impact energy and give important information about its anticipated and desired deformation behavior when incorporated into composite armor.

\section{Conclusions}

High strain rate compression behavior of a plainweave glass fiber/epoxy composite in a direction normal to the fiber plane was determined for strain rates between $1.4 \times 10^{-4}$ and $1.1 \times 10^{3} \mathrm{~s}^{-1}$. In the studied strain rate regime, the modulus and failure strength were found to be rate sensitive. Microscopic observations have shown that the failure of the composite occurred via matrix fracture and delamination. The debonded and pulled-out rubber particles observed on the fracture surface of the composite tended to indicate a significant effect of these particles on the fracture toughness of the composite.

\section{References}

[1] Composite Structure Design Guide, Composite Armored Vehicle program, United defense L. P., 1997-1998.

[2] M. Güden, I.W. Hall, High strain-rate compression testing of a short-fiber reinforced aluminum composite, Mater. Sci. Eng. A232 (1997) 1.

[3] G. Ravichandran, G. Subhash, Critical appraisal of limiting strain rates for compression testing of ceramics in a split Hopkinson pressure bar, J. Am. Ceram. Soc. 77 (1994) 263.

[4] B.A. Gama, J.W. Gillespie, H. Mahfuz, R.P. Raines, A. Jeelani, S. Jeelani, T.A. Bogetti, B. Fink, High strain-rate behavior of plain-weave S2 glass/vinyl ester composites, J. Comp. Mater. 35 (2001) 1201.

[5] Ö. Akil, U. Yıldırım, M. Güden, I.W. Hall, Effect of strain rate on the compression behaviour of a woven fabric S2-glass fiber reinforced vinyl ester composite, Polym. Test. 22 (2003) 883.

[6] L. Sierakowski, Strain rate effects in composites, Appl. Mech. Rev. 50 (1997) 741.

[7] M.V. Hosur, M. Ayda, U.K. Vaidya, A. Mayer, S. Jeelani, Effect of stitching and weave architecture on the high strain rate compression response of affordable woven carbon/epoxy composites, Compos. Struct. 59 (2003) 507.

[8] J. Harding, Effect of strain rate and specimen geometry on the compressive strength of woven glass reinforced epoxy laminates, Composites 24 (4) (1993) 323. 
[9] A.M.A. El-Habak, Mechanical behavior of woven glass fibre-reinforced composites under impact compression load, Composites 22 (1991) 129.

[10] M.Z.S. Khan, G. Simpson, E.P. Gellert, Resistance of glass-fibre reinforced polymer composites to increasing compressive strain rates and loading rates, Composite A 31 (2000) 57.

[11] K. Oguni, G. Ravichandran, Dynamic compressive behavior of unidirectional E-glass/vinyl ester composites, J. Mater. Sci. 36 (2001) 831. 